\title{
Index System and Its Application of Fuzzy Assessment on Undergraduates' Employment Quality
}

\author{
Jia'nan Chen ${ }^{1,2} *$ \\ Beijing University of Technology, Beijing \\ Collaborative Innovation Center of Beijing Society- \\ Building \& Social Governance \\ Beiing, China \\ chenjianan@bjut.edu.cn \\ * Corresponding Author \\ Dongsheng Yang ${ }^{1}$ \\ Beijing University of Technology, Beijing \\ Beiing, China \\ yangdongsheng@bjut.edu.cn
}

\begin{abstract}
Assessment index reflects assessed contents and the choice of assessment method. A scientific assessment index system is in favor of exactly assessing the quality of talent cultivation, as well as guiding the enhancement of the quality. This paper intends to establish an index system of fuzzy assessment of undergraduates' em-ployment quality through the theoretical approach of management science and engineering and apply it into the guidance of undergraduates' employment from Beijing University of Technology.
\end{abstract} quality

Keywords-index sysenm; fuzzy mathematics; employment

\section{INTRODUCTION}

In 1999, the implementation of college admission expansion policy has transformed higher education from elite mode to public mode. Confronted with the rapid outspreading of colleges' scales, policy makers have to answer a question: whether the economic demand for highly educated talents and the talent supply from college has reached a balance? An intuitional index for answering this question is the employment situation of college undergraduates. Before college admission expansion in 1999, fresh graduates always had multiple employment choices; however, after the expansion in 1999, especially after 2001, Ministry of Education started to pay attention to undergraduates' employment rate--their first employment rate basically remained at $75 \%$ or so, which meant that $25 \%$ fresh graduates were unemployable. It is worth noting that in 2008 and 2009, the first employment rate, affected by worldwide financial crisis, fell down below $70 \%$ for the first time--it remained at around 68\%[1]. Thus, the grim picture for fresh graduates' employment could be seen and key universities, as a result, had to consider the subsequent influence on their own enrollment exerted by the employment rate and employment quality.

\author{
Hongfang Zhou ${ }^{1}$ \\ Beijing University of Technology, Beijing \\ Beiing, China \\ zhouhongfang@bjut.edu.cn
}

\section{LITERATURE REVIEW}

In accordance with requirements of college talents' cultivation, A number of experts and scholars of education have established assessment index from various perspectives which can be classified as two categories: one is from the perspective of elements that affects the quality of college talents' cultivation; the other is from the perspective of the cultivation's standards and components.

\section{A. Quality Elements}

In the first category, Ni lijuan has put forward five elements: the correctness of a university's positioning, the normalization of teaching, the importance of practical teaching, the scientificity of teaching assessment and teaching method; in line with an all-round, coordinated, and sustainable talent cultivation quality concept that take people as the foremost[2], Sun Mingbao and Li Xinping have designed first-class indexes-guiding ideas, teaching staff, teaching condition, majors and courses, teaching management, teaching and learning atmosphere, teaching effects, and special projects - to assess talent cultivation quality[3]; Zhang Dejiang assesses talent cultivation quality from seven aspects: the central status of teaching, teachers' devotion, students' right to handle their own study, teaching mode, students' learning status, multimedia teaching effects, and moral education[4].

\section{B. Standards and Components}

In the second category, Zhang Pei has designed seven first-class indexes, each attached by several second-class indexes, to assess the quality of talent cultivation. The seven first-class indexes contain elements composing the quality of talent cultivation, the optimized rationality of designing course system and teaching contents, the basic quality of professional teaching resources, the basic quality of newly-enrolled students, the quality of theoretical teaching, the quality of professional and practical teaching, 
the improvement of professional teaching condition, and the all-round quality of graduates[5].Zhang Yunxia, from a strategic perspective, has designed indexes such as a guarantee system of talent cultivation quality, the employment rate of graduates, the salary comparison rate of graduates, the satisfaction rate of graduates, the satisfaction rate of employees, and the cognition degree of talent quality brand, in order to assess the quality of university's talent cultivation[6]; Shi Huamin has put forward the social-need-oriented principle of talent cultivation to build up three assessment indexes: the construction of knowledge structure,the construction of ability structure, and moral education[7]. In addition, Dai Ning and Cai Baping[8], Sun Zeping[9], Zhou Yan[10], and other scholars have also set up assessment indexes from the aspects of composition and contents of university's talent cultivation quality standards.

\section{Further Study}

Assessment index reflects assessed contents and the choice of assessment method. A scientific assessment index system is in favor of exactly assessing the quality of talent cultivation, as well as guiding the enhancement of the quality. College talent cultivation should stick to guidelines for college management that take students as the foremost and promote students' all-round development, improve the quality of talent cultivation that lays emphasis on knowledge imparting, ability training, and quality enhancing. Therefore, assessment index needs to focus on knowledge, ability, quality, and other related elements; also it attaches importance on the feasibility of index to design index for assessment.

\section{ESTABLISH ASSESSMENT INDEX SYSTEM OF EMPLOYMENT QUALITY}

Quality is the eternal theme and the lifeline of higher education's development. Improving talent cultivation quality is the core issue of higher education's development and the fundamental requirement of enhancing the international competitiveness of China's higher education. So the standards for college talent cultivation quality and the idea of it become a focus of many experts and scholars[11]. This paper intends to establish an index system of fuzzy assessment of undergraduates' employment quality through the theoretical approach of management science and engineering and apply it into the guidance of undergraduates' employment from Beijing University of Technology(BJUT for short). As for the quality of undergraduates' employment, many indexes are incapable of measuring the complementation degree of the employment. Therefore, this paper, by introducing membership function to set up a membership matrix of assessing the competitiveness of undergraduates' employment, combines conventional qualitative research and quantitative research to translate them into pure quantitative research.

\section{A. Index Set}

In the light of aspects of undergraduate' employment quality, this paper categorizes various elements that influence assessed objects into primary and secondary elements. The element set mentioned above is the index set to be assessed, which can be represented in the same manner as $U=\left(u_{1}, u_{2}, \ldots, u_{m}\right)$. The set, consisting of multiple primary and secondary elements, indicates from which aspects to assess objects. The ultimate goal of this paper's fuzzy assessment system is to feedback through undergraduate' employment and to make comprehensive assessment on the employment quality of undergraduates from different majors( or from different Colleges). For that reason, contributions to general objective made by all basic elements needs to be considered.

In order to assess undergraduates' employment quality scientifically, this paper, on the basis of referring a large amount of literature, puts forward a new set of assessment index system for the quality of undergraduates' employment. This system consists of five first-class indexes: students' satisfaction degree of employees, students' satisfaction degree of employment guidance, preparation of each student's job hunting, teaching contents' practicability, and students' satisfaction degree of teaching. Such a design aims to investigate the teaching and employment guiding of colleges and their Colleges before their undergraduates finish their study, consider these students' subjective initiative during their job hunting, and assess the overall condition of employment quality from employees' perspective.

To exactly and easily collect and assess statistics, this paper classifies each first-class index into several secondclass index, as shown in Tab.1. When selecting secondclass indexes, this paper should consider if these secondclass indexes belong with the first-class indexes' concepts, and concepts of second-class indexes, when the indexes belong to the same first-class index, cannot repeat, which means each second-class index is a clear explanation of their first-class index in certain aspect.

TABLE I. REMARK SET OF ASSESSMENT INDEX OF BJUT UNDERGRADUATES' EMPLOYMENT QUALITY

\begin{tabular}{|c|c|c|c|c|c|c|c|c|}
\hline First-class index & $\begin{array}{c}\text { First- } \\
\text { class } \\
\text { weights }\end{array}$ & Second-class index & $\begin{array}{l}\text { Second- } \\
\text { class } \\
\text { weights }\end{array}$ & Ideal & Good & Average & Sub-standard & Disappointing \\
\hline \multirow{4}{*}{$\begin{array}{l}\text { Students' } \\
\text { satisfaction } \\
\text { degree of } \\
\text { employees }\end{array}$} & \multirow{4}{*}{0.198} & Salary & 0.033 & Quite satisfied & Satisfied & Average & Dissatisfied & $\begin{array}{c}\text { Quite } \\
\text { dissatisfied }\end{array}$ \\
\hline & & Welfare & 0.033 & Quite satisfied & Satisfied & Average & Dissatisfied & $\begin{array}{c}\text { Quite } \\
\text { dissatisfied }\end{array}$ \\
\hline & & Work environment & 0.033 & Quite satisfied & Satisfied & Average & Dissatisfied & $\begin{array}{c}\text { Quite } \\
\text { dissatisfied }\end{array}$ \\
\hline & & Relationships among colleagues & 0.033 & Quite satisfied & Satisfied & Average & Dissatisfied & Quite \\
\hline
\end{tabular}




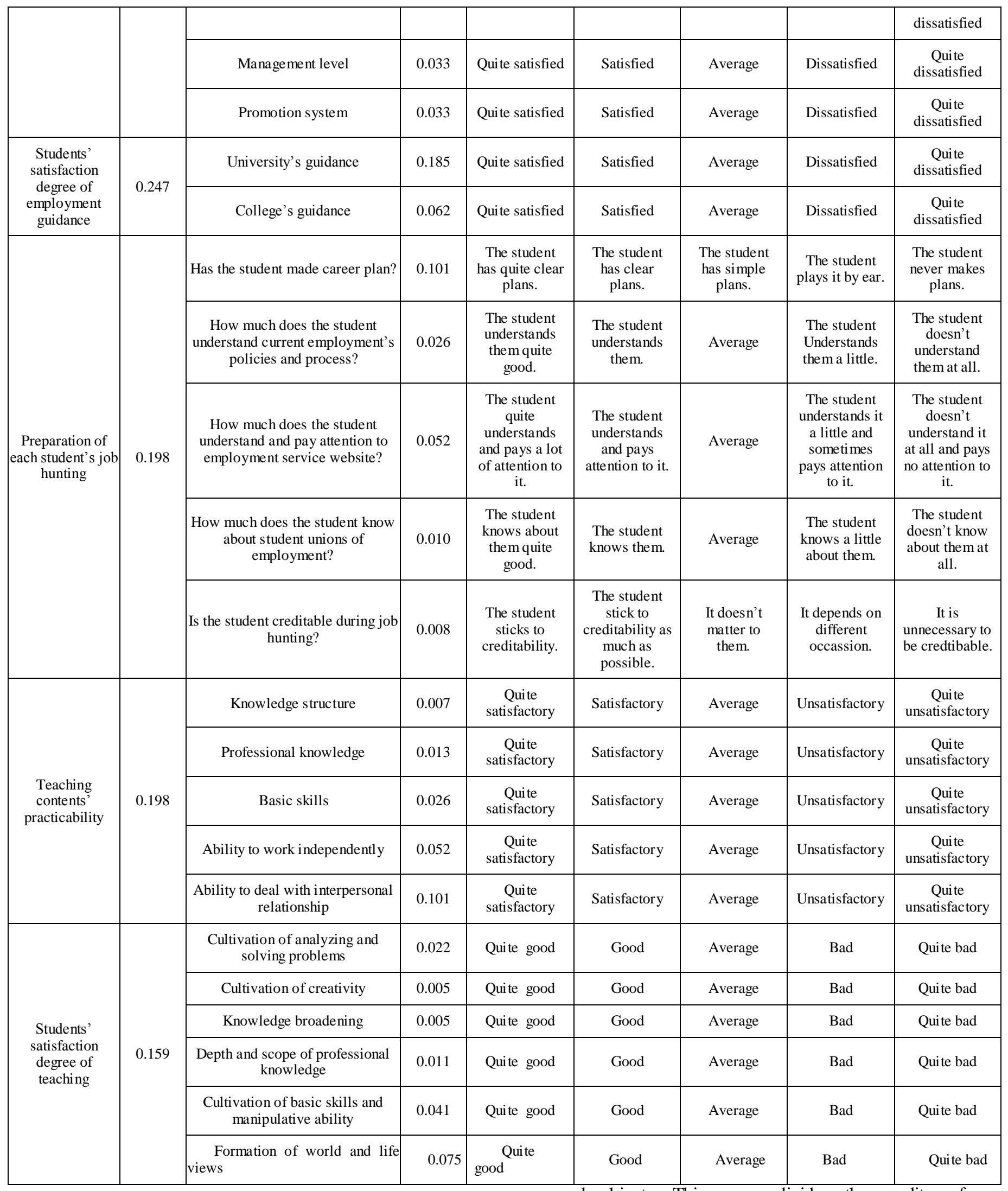

\section{B. Remark Set}

Remark set is represented as Set $V$, i.e. $V=\left(v_{1}, v_{2}, \ldots, v_{k}\right)$, in which ${ }^{k}$ stands for the number of remarks and is actually a division of variable intervals of assessed objects. This paper divides the quality of undergraduates' employment into five levels: disappointing, sub-standard, average, good, and ideal. Employment quality has been divided into intervals by remark set, but in actual counting, especially in questionnaire investigation, remarks of every index must 
be approachable and accord with context. Hence this paper resets remark set of every second-class index, as shown in Tab. 1.

\section{Weight Set}

In fuzzy and comprehensive assessment, weight exerts great influence on ultimate results since different weights will obtain utterly different results. Therefore, whether selected weight is fit determines whether model succeeds or fails. Comprehensive assessment should be a fuzzy subset $\underset{\sim}{B}=\left(b_{1}, b_{2}, \ldots, b_{k}\right) \in \wp(V)$ affiliated with $V$, and $b_{h}, \quad(h=1,2, \ldots, k)$ reflects the low order of $v_{h}$ in the sequence of $h$ in comprehensive assessment, i.e. the membership degree of $v_{h}$ to fuzzy set $\stackrel{B}{\sim}$, which can be presented as $\underset{\sim}{\sim}\left(v_{h}\right)=b_{h}$. Depending on the weights of each element, $\stackrel{B}{\sim}$, the comprehensive assessment, should be $U$ 's fuzzy subset, which can be presented as $W=\left(w_{1}, w_{2}, \ldots, w_{m}\right) \in \wp(U)$ and $\sum_{i=1}^{m} w_{i}=1$ with $w_{i}$ standing for the $i$ th element's weight. Once the weight $W$ is given, a comprehensive assessment $\underset{\sim}{B}$ can be obtained correspondingly. This paper, via Analytic Hierarchy Process, AHP for short), collects weight information. AHP can not just ensure the model's systematicness and rationality, but also enables decision makers to take full advantage of their valuable experience and discretion to provide powerful policy support to regulation and decision issues. The setting of the weight set of BJUT undergraduates' employment quality assessment index is also shown in Tab.1.

In line with AHP's process and algorithm, this paper obtains first-class and second-class index weights of undergraduates' employment quality assessment index, which offers weight set for fuzzy assessment in the following text. Those weights show the differences of each index's importance among the whole system so as to reflect imbalanced influences on employment quality caused by colleges' education and students' own preparation. It can be seen from the results that : the weights of six second-class indexes affiliated with firstclass index "Students' satisfaction degree of employees" are the same, indicating that the six indexes possess the equal importance; in first-class index "students' satisfaction degree of employment guidance", students' satisfaction degree of university's guidance is as almost as three times as that of College's, manifesting greater influence from university level; in first-class index "preparation of each student's job hunting", the weight of "has the student made career plan" accounts the most, pointing that students' subjectivity effects more employment quality than employment information channels; in first-class index of "Teaching contents" practicability", the weight of "ability to deal with interpersonal relationship" occupies the most percentage,

On the basis of this index system, this paper, referring the establishment procedure of fuzzy and balanced score card model, gets corresponding weight set and fuzzy assessment matrix through investigation and interviews so as to make comprehensive and fuzzy assessment of firstclass category and general goal.

\section{Algorithm Process OF FuZZY AsSESSMENT}

Fuzzy and comprehensive assessment is an effective multi-factor decision method to comprehensively assess objects affected by multiple factors, so this method can also be claimed as fuzzy and comprehensive decision or fuzzy multiple decision.

Fuzzy and comprehensive assessment can usually be separated into two steps: the first step is make single factor assessment, and the second step is to make comprehensive assessment of overall factors. The benefits of this simple mathematic model is easy to master and can exactly assess complicated problems of multi factors and multi levels. Thus, it is irreplaceable by other mathematic branches and models. Also it can assess objects one by one and has the only value to them, free from influences of the set in which objects are. The specific procedures of fuzzy hierarchy analyst model is as follows.

\section{A. Construct Fuzzy Assessment Matrix}

Each factor $u_{i}$ is counted as an assessment $f\left(u_{i}\right)$, so it can be regarded as fuzzy mapping $\underset{\sim}{f}$ from $U$ to $V$.

$$
\begin{gathered}
f: U \rightarrow \wp(V) \\
u_{i} \mapsto \underset{\sim}{f}\left(u_{i}\right) \in \wp(V)
\end{gathered}
$$

From $\stackrel{f}{\sim}$, an induced fuzzy linear transformation $\underset{\sim}{T_{f}}$ from $U$ to $V$ can be regarded as the mathematic model of the comprehensive assessment $\stackrel{B}{\sim}$ resulted from weight $A$.

Consequently, fuzzy mapping $\underset{\sim}{f}$ can induce fuzzy

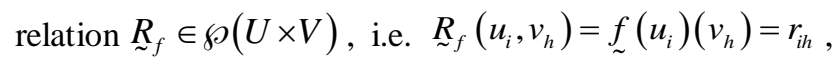
among which ${\underset{\sim}{R}}_{f}$ can be represented as fuzzy matrix $\underset{\sim}{R} \in \mu_{m \times k}$ :

$$
\underset{\sim}{R}=\left[\begin{array}{cccc}
r_{11} & r_{12} & \cdots & r_{1 k} \\
r_{21} & r_{22} & \cdots & r_{2 k} \\
\vdots & \ddots & \cdots & \vdots \\
r_{m 1} & r_{m 2} & \cdots & r_{m k}
\end{array}\right]
$$

$\stackrel{R}{\sim}$ is called as single-factor assessment matrix, among which $r_{i h}$ means starting from factor $x_{i}$ and this assessed object can be counted as membership degree of $v_{h}$. To put it specifically, ${ }^{r_{i h}}$ stands for the frequency distribution of the ${ }^{i}$ th factor $x_{i}$ in the $h_{\text {th assessment }} v_{h}$, and the frequency distribution is generally normalized to meet the demand of $\sum_{h=1}^{k} r_{i h}=1$. As such, matrix $\underset{\sim}{R}$ itself doesn't have dimension so particular processing is unnecessary.

\section{B. Calculate the Value of Fuzzy and Comprehensive Assessment}

fuzzy relation $\underset{\sim}{R}$ can induce fuzzy linear transformation $\underset{\sim f}{T}$ from $U$ to $V$. Thus, $(U, V, \underset{\sim}{R})$ compose a fuzzy and comprehensive assessment model. 
In order to consider each index's influence on students' job-searching competitiveness, this paper applies weighted average model to weight $W$ and fuzzy matrix $\underset{\sim}{R}$ to make synthetic algorithm, which means calculating via model $^{M(\cdot,+)}$. The comprehensive assessment formula is:

$$
\underset{\sim}{B}=W \cdot \underset{\sim}{R}
$$

The function of this formula is like the function of converter, as shown in Fig.1:

$$
\stackrel{W \in \wp(U)}{\longrightarrow} \underset{\sim}{\underset{\sim}{R} \in \wp(U \times V)} \stackrel{\stackrel{\sim}{B}=W \cdot R \in \wp(V)}{\longrightarrow}
$$

Figure 1. Figure 1. The matrix converting of fuzzy assessment's membership degree

When a weight $W \in \wp(U)$ is input, and a comprehensive assessment will be output:

$$
\underset{\sim}{B}=W \bullet \underset{\sim}{R} \in \wp(V)
$$

When $\sum_{h=1}^{k} \underset{\sim}{\underset{b}{b}} \neq 1$ is normalized, $\underset{\sim}{\bar{B}}=\left(\bar{\sim}_{1}, \bar{\sim}_{\sim}, \ldots, \bar{\sim}_{k}\right)$ can be obtained if $\bar{\sim}_{h}=b_{h} / \sum_{h=1}^{k}{\underset{\sim}{h}}_{h}$ is set.

In light with fuzzy distribution's principle, each assessment index specifically reflects assessed objects' distribution status. Therefore, to avoid the loss of assessed information, score set $F=\left(f_{1}, f_{2}, \ldots, f_{k}\right)$ is introduced and it is column vector with the value of $k$ equaling that of assessment set. $f_{h}$ represents the score of the $h$ th assessment. With 100 as the full remarks, through arithmetic scoring this paper can get $F=(20,40,60,80,100)$. And with membership degree matrix multiplying score set, this paper can get the comprehensive score of fuzzy assessment, as presented via the formula $Z=\underset{\sim}{\bar{B}} \square F$ with $Z$ standing for the fuzzy assessment score of undergraduates' employment quality.

\section{EMPIRICAL ANALYSIS}

\section{A. Data Source}

In order to empirically analyze fuzzy assessment of employment quality via the index system this paper has built, the author, with assistance from BUT employment service center, organized a survey on employment condition of this university's graduates of 2015。 1755 effective questionnaires have been return, among which 1104 questionnaires come from undergraduates, taking up $37.31 \%$ of the total 2959 undergraduates.

\section{B. Data Collation}

The assessment set defines five statuses of employment quality and each index has its own presenting way according to specific context, as shown in the questionnaire. However, to meet the demands of fuzzy and comprehensive assessment, data, when in collation, should be classified into the five statuses, of which membership degree matrix needs to be determined by degree proportion. Two problems should be noted for the sake of reliability: the first one is that the number of interviewees needs to be enough, and only in this situation can the degree proportion verge on membership degree; and the second one is that interviewees must have a quite good understanding about assessed objects, some assessed objects of professional fields in particular. For this paper, the number of interviewees is enough and every one of them are direct carriers of employment quality.

\section{Assessment Results}

According to index system and fuzzy assessment algorithm, this paper gets the employment quality statistics of 2015 undergraduates from 16 colleges in BJUT, which are presented through membership degree matrix and

\begin{tabular}{|c|c|c|c|c|c|c|}
\hline College & $\begin{array}{c}\text { Ideal } \\
100\end{array}$ & $\begin{array}{c}\text { Good } \\
80\end{array}$ & $\begin{array}{c}\text { Average } \\
\quad 60\end{array}$ & $\begin{array}{c}\text { Sub-standard } \\
40\end{array}$ & $\begin{array}{c}\text { Disappointing } \\
20\end{array}$ & Score \\
\hline College of Material & 0.13 & 0.49 & 0.30 & 0.07 & 0.02 & 72.88 \\
\hline College of Electric Control & 0.24 & 0.49 & 0.23 & 0.03 & 0.00 & 78.94 \\
\hline College of Environment and Energy & 0.16 & 0.47 & 0.30 & 0.04 & 0.02 & 74.21 \\
\hline College of Mechanical and Electrical Technology & 0.18 & 0.52 & 0.27 & 0.03 & 0.00 & 76.79 \\
\hline College of Computing & 0.20 & 0.55 & 0.22 & 0.02 & 0.00 & 78.61 \\
\hline College of Civil Engineering & 0.17 & 0.57 & 0.23 & 0.02 & 0.01 & 77.37 \\
\hline College of Architectural Planning & 0.23 & 0.44 & 0.29 & 0.03 & 0.00 & 77.32 \\
\hline College of Transportation & 0.05 & 0.55 & 0.32 & 0.08 & 0.00 & 71.06 \\
\hline College of Economics and Management & 0.18 & 0.52 & 0.27 & 0.03 & 0.01 & 76.54 \\
\hline College of Humanities & 0.19 & 0.57 & 0.21 & 0.03 & 0.01 & 78.01 \\
\hline College of Software & 0.21 & 0.49 & 0.25 & 0.05 & 0.00 & 76.81 \\
\hline College of Life Science & 0.22 & 0.47 & 0.24 & 0.05 & 0.01 & 76.80 \\
\hline
\end{tabular}
comprehensive scores, as shown in Tab.2.

TABLE II. FUZZY ASSESSMENT OF BJUT UNDERGRADUATES’ EMPLOYMENT QUALITY ASSESSMENT INDEX SYSTEM 


\begin{tabular}{|c|c|c|c|c|c|}
\hline College of Experiment & 0.17 & 0.48 & 0.31 & 0.04 \\
\hline College of Mathematics and Physics & 0.16 & 0.48 & 0.27 & 0.05 & 0.03 \\
\hline College of Foreign Languages and Literature & 0.17 & 0.45 & 0.33 & 0.05 \\
\hline College of Arts & 0.18 & 0.44 & 0.34 & 0.04 \\
\hline
\end{tabular}

The fuzzy assessment score shows that the top three colleges of employment quality are College of Electric Control (78.94), College of Computing (78.61), and College of Humanities (78.01). Viewed from membership degree matrix, the top three colleges in ideal status are College of Electric Control (24\%), College of Architectural Planning (23\%), and College of Life Science $(22 \%)$. In conclusion, the advantage of this assessment method lies in not only representing an assessed object's status with one final result, but also offering more perspectives to observe their features to avoid holding a part as the whole. The assessed results of BJUT can be a reference for the university's administration departments to adjust employment service, and they can also be the foundation of performance appraisal. In further study, the assessed results will get more in-depth analysis.

\section{REFERENCES}

[1] Liu Yanru. The Research of Initial Employment of University Graduates in the Social Capital Perspective [D]. Central China Normal University, 2012.

[2] Ni Lijuan, Chen Hui. Analysis on Quality Factors of University Training [J]. Heilongiang Education(Higher Education Research \& Appraisal), 2007:40-41.

[3] Sun Mingbao, Li Xinping. The Construction of Quality Assessment Index System of Talents Training Based on the Hierarchy Analytic Process-Take an example of pedagogical

training in local colleges and institutes [J]. Journal of Hunan Institute of Science and Technology (Natural Sciences), 2011, 24:27-30.

[4] Zhang Dejiang. Study on Affecting Factors and Countermeasures about Education Quality [J]. China University Teaching, 2012:1113.

[5] Zhang Pei. Research on Quality Evaluation System for the Training of Undergraduates Majoring in E-Commerce[D]. Hefei University of Technology, 2009.

[6] Zhang Yunxia. Quality Evaluation Mode of University Personnel Training Based on Strategy [J]. Journal of Xinxiang University( Social Sciences Edition) 2012, 26:143-145.

[7] Shi Huamin. Research of building the evaluation system about quality of talents in higher engineering education [D]. Harbin University of Science and Technology, 2013.

[8] Dai Ning, Cai Baping. Building Quality Standards of Talents Training in Police Colleges under Perspective of Capability[J]. Journal of Sichuan Police College, 2008, 20:62-67.

[9] Sun Zeping, Qi Xingui, He Wanguo. Practicing and Exploring of Applied Talent Cultivation System Building-Taking Chongqing University of Arts and Sciences as an Example [J]. Chongqing Higher Education Research, 2013, 1:54-58.

[10] Zhou Yan. Study on Quality Evaluation Criteria of Accounting Professionals' Training in Higher Vocational Colleges[J]. Knowledge Economy, 2013:179-180.

[11] Peng Zhenzhen, Li Jian, Ma Ji. Review of Talents Training' Quality in University [J]. Education Teaching Forum, 2014. 